\title{
Uma análise da dimensão "tipo de governança" em Unidades de Conservação da Natureza no Brasil
}

\section{An analysis of the type dimension of governance in Nature Conservation Units in Brazil}

Carlos André Lu₹ Jeronymo - Doutor em Meio Ambiente pela Universidade do Estado do Rio de Janeiro (UERJ). Pesquisador convidado no grupo de estudos COGERE/UERJ. E-mail: carlosjeronymo@gmail.com

Elmo Rodrigues da Silva - Doutorado em Saúde Pública pela Fundação Oswaldo Cruz (FIOCRUZ). Professor da Universidade do Estado do Rio de Janeiro (UFRJ). E-mail: elmorodrigues@yahoo.com.br

Kenny Tanizaki Fonseca - Doutorado em Geoquímica Ambiental pela Universidade Federal Fluminense (UFF). Professor da Universidade Federal Fluminense. E-mail: kenny. fonseca@gmail.com

\section{Resumo}

Neste trabalho questiona-se o Sistema Nacional de Unidades de Conservação da Natureza (SNUC) e o Decreto n ${ }^{\circ} 4.340 / 2000$, que o regulamenta, possibilitando as UC de exercerem todas as combinações possíveis de tipos de governança de áreas protegidas, tal como orienta o Sistema Internacional de Áreas Protegidas (SIAP) da International Union for Conservation of Nature (IUCN) para os Sistemas Nacionais de Áreas Protegidas (SNAPs) evitarem entraves à gestão e à promoção de conflitos. O objetivo deste artigo é analisar os tipos de governança de áreas protegidas que cada categoria de manejo de UC pode desempenhar. A metodologia envolveu o método hipotético-dedutivo e seus desdobramentos: pesquisa exploratória de gabinete, por meio de revisão de literatura e leitura crítica. Identificou-se que as diretrizes do SNUC e do Decreto $n^{\circ} 4.340 / 2002$ não permitem que as categorias de manejo de UC exerçam todos os tipos de governança de áreas protegidas, o que causa entraves à gestão.

\section{Palavra-chave}

Áreas Protegidas. Governança. Unidade de Conservação da Natureza. SNUC.

\begin{abstract}
This work questions if the SNUC enables $\mathrm{UC}$ to exercise all possible combinations of governance types on protected area, as directed by the International Protected Areas Systems (SIAP) of International Union for Conservation of Nature (IUCN) to the National Protected Areas Systems (SNAP) to prevent problems to conflict management and promotion. This article main objective is to analyze the types of protected area governance that each SNUC management category can exercise. The methodology of this paper involved the hypothetical-deductive method and its procedures: an exploratory overview, through a literature review and a critical reading of SNUC and its regulatory decree. It was identified that the SNUC guidelines and of Decree n. 4.340/2002 does not allow management categories of UC to exercise all types of protected area governance, which causes management encumbers.
\end{abstract}

\section{Keywords}

Governance. Nature Conservation Units. Protected Areas. SNUC. 


\section{INTRODUÇÃO}

Ronald H. Coase, em The Nature of The Firm, e, posteriormente, Oliver E. Williamson, em Corporate Governance, são reconhecidos como aqueles que criaram as teorias da governança (COESE, 1937 apud MATIAS-PEREIRA, 2010; WILLIAMSON, 1975 apud MATIAS-PEREIRA, 2010). Porém, o Banco Mundial foi aquele que definiu primeiro o seu conceito. Em seu livreto, a governança é definida como: a "maneira pela qual o poder é exercido na gestão dos recursos econômicos e sociais de um país para o desenvolvimento" (WORLD BANK, 1992, p. 01, tradução nossa).

De acordo com as teorias da governança de Coese (1937) e Williamson (1975) apud Matias-Pereira (2010) tornaram possível compreender os princípios, mecanismos e objetivos que permitem uma melhor interação com atores sociais no campo da administração. A governança possibilitou implementar ações que permitem uma participação mais efetiva dos atores sociais na gestão de um recurso natural, além de se coordenar ações de forma a produzir melhores resultados coletivos.

Durante o $5^{\circ}$ World Park Congress, Graham, Amos e Plumptre (2003), por meio do Institute On Governance (IOG), definiram a governança de áreas protegidas como a influência mútua entre as estruturas, processos e tradições que determinam como são exercidos o poder na tomada de decisão e a responsabilidade na prestação de contas e se a sociedade e os atores sociais possuem voz durante a criação, implantação e gestão de um sítio protegido.

Fundamentalmente, para os autores, a governança de áreas protegidas envolve poder, autoridade, responsabilidade e responsividade, ou seja, quem toma a decisão de fato, quem têm influência nela, o quanto se é transparente sobre as informações e como aqueles que tomam as decisões são responsabilizados, de acordo com os direitos legais, costumeiros ou legítimos que envolvem a temática de áreas protegidas ou um sítio (GRAHAM; AMOS; PLUMPTRE, 2003; MULONGOY; CHAPE, 2004).

De acordo com esse pensamento, um cenário de governança de áreas protegidas depende da combinação entre políticas, práticas e instituições, explícitas e implícitas, que afetam os sítios protegidos. A governança de áreas protegidas depende desde a existência de políticas públicas até às práticas de comportamentos, significados, investimentos e impactos ambientais positivos ou negativos (BORRINI et al., 2013). 
Nesse contexto, em 2013, a International Union for Conservation of Nature e a World Commission on Protected Areas (IUCN-WCPA) veem a governança de áreas protegidas como crucial para: a) o alcance dos objetivos de um sítio protegido (eficácia da gestão); b) a partilha justa dos ônus e bônus da área protegida (equidade da gestão); c) a prevenção, resolução ou estabilização de conflitos entre atores sociais e a área protegida; e, (d) a geração ou sustentação do apoio da sociedade, por meio da prestação de contas (BORRINI et al., 2013) ${ }^{1}$.

Segundo Borrini et al. (2013), as duas principais dimensões da governança de áreas protegidas são: tipo e qualidade. Os tipos de governança de áreas protegidas são: (a) Governança do Estado; (b) Governança Compartilhada ou Cogestão; (c) Governança Privada; (d) Governança Comunitária. A dimensão da qualidade remete à boa governança (GRAHAM; AMOS; PLUMPTRE, 2003).

No Brasil, o conceito equivalente às áreas protegidas do Sistema Internacional de Áreas Protegidas (SIAP) da International Union for Conservation of Nature (IUCN) são as Unidades de Conservação da Natureza (UC) (PUREZA; PELLIN; PADUA, 2015), sendo o Sistema Nacional de Unidades de Conservação da Natureza (SNUC) o marco legal a Lei no 9.985 (BRASIL, 2000) para criação, implantação e gestão de sítios protegidos, inclusive para o processo de governança.

As UC são espaços com características relevantes que estão sob o regime especial de administração do poder público. Para uma área ser reconhecida como UC, ela deve ter seus limites cartográficos demarcados, os objetivos de proteção ambiental determinados e ser legalmente instituída, por meio de ato legal do poder público. Dentro dessa perspectiva, os recursos naturais e as águas jurisdicionais que estiverem no interior de uma UC são considerados como parte dela e, por isso, deve-se oferecer garantias adequadas às suas proteções (BRASIL, 2000).

O SNUC possui 12 categorias de manejo de UC separadas em dois grupos: o de Proteção Integral e o de Uso sustentável. Essa Lei associa cada categoria de manejo a um objetivo primário de proteção ambiental específico (BRASIL, 2000).

Este trabalho busca responder se o SNUC e o Decreto n ${ }^{\circ} 4.340$ (BRASIL, 2002), que o regulamenta, seguem as orientações do SIAP da IUCN para gestão de áreas. A hipótese é que a existência de diretrizes no SNUC e no Decreto $\mathrm{n}^{\circ} 4.340 / 2002$ impossibilitam que cada categoria de manejo de UC do SNUC exerça todas as combinações possíveis de tipo de governança, o que causa entraves à governança e conflitos entre UC e atores sociais. Essa premissa tem como base Vallejo (2017), que menciona que o SNUC se constitui numa camisa

1 Os princípios da governança de áreas protegidas definidos por Graham, Amos e Plumptre (2003) são rediscutidos e redesenhados pelo manual da IUCN-WCPA aqui citado. 
de força aos gestores de UC, principalmente no tocante à dimensão humana das áreas protegidas.

O objetivo deste trabalho foi identificar entraves no SNUC e sua regulamentação ao alcance da governança em UC, conforme as recomendações do SIAP da IUCN (WORBOYS et al., 2015) para os Sistemas Nacionais de Áreas Protegidas (SNAPs). Os objetivos específicos foram: (i) levantar e descrever os tipos de governança de áreas protegidas; (ii) levantar os tipos de governança de cada categoria de UC determinados pelo SNUC e o Decreto $\mathrm{n}^{\circ} 4.340 / 2002$; (iii) analisar se o SNUC e o Decreto $n^{\circ} 4.340 / 2002$ seguem as recomendações do SIAP da IUCN para os SNAPs.

Almeja-se que com este trabalho possa-se subsidiar os gestores com informações sobre alguns dos entraves para uma boa governança em UC.

\section{METODOLOGIA}

A metodologia deste trabalho envolveu o método hipotético-dedutivo e seus desdobramentos: pesquisa exploratória de gabinete, por meio de revisão de literatura integrativa e uma pesquisa documental.

A consulta à literatura foi conduzida em páginas da internet como Google Scholar, portal Scielo, portal de periódicos da Coordenação de Aperfeiçoamento de Pessoal de Nível Superior (CAPES), em busca de artigos, livros, monografias (graduação, pós-graduação lato sensu, dissertações e teses), trabalhos publicados em anais de congressos, estudos de especialistas, regulamentos legais e documentos oficiais. Os procedimentos de consulta se deram entre março de 2015 e abril de 2019. Eles tiveram como foco a governança em áreas protegidas e, mais especificamente, em UC.

A busca da literatura teve como base os seguintes indexadores de pesquisa: Governança; Unidade de Conservação da Natureza; Áreas Protegidas; Governance; Nature Conservation Units; Protected Areas. A escolha dos textos para compor a pesquisa foi orientada por meio do problema norteador deste trabalho, a hipótese e os objetivos. Os indexadores de pesquisa também serviram para separar os textos escolhidos em temas.

A pesquisa documental teve como foco o SNUC e o Decreto n ${ }^{\circ} 4.340 / 2002$ que o regulamenta, pois o SNUC é a política pública que cria o SNAP brasileiro e nele constam os princípios, diretrizes, objetivos, determinações e instrumentos para gestão de UC, inclusive para governança. Durante a pesquisa documental foi conduzida uma leitura crítica dos dois regulamentos legais. 
A leitura crítica do SNUC e seu decreto regulamentador teve como lente de observação e análise a dimensão tipo de governança definida por Graham, Amos e Plumptre (2003) e rediscutida no manual da IUCN para governança em áreas protegidas (BORRINI et al., 2013), além das recomendações do SIAP da IUCN (WORBOYS et al., 2015) para os Sistemas Nacionais de Áreas Protegidas (SNAPs).

O trabalho foi estruturado em três itens: i) uma descrição dos tipos de governança em áreas protegidas, principalmente com base nos manuais da IUCN elaborados por Graham, Amos e Plumptre, (2003), Borrini et al. (2013) e Worboys et al. (2015) e um levantamento das recomendações do SIAP da IUCN para os SNAPs; ii) um panorama da governança em UC no Brasil, conforme o SNUC e do Decreto no 4.340/2002; e iii) uma análise se o SNUC e seu Decreto regulamentador seguem as recomendações do SIAP da IUCN para os SNAPs.

\section{DIMENSÃO TIPO DA GOVERNANÇA EM ÁREAS PROTEGIDAS E AS RECOMENDAÇÕES DO SIAP DA IUCN PARA OS SNAPS}

Os tipos de governança em áreas protegidas podem ser diferenciados ao analisar quem detém o poder e a autoridade na tomada de decisão e quem possui a responsabilidade sobre a gestão do sítio protegido e perante a prestação de contas à sociedade (responsividade). A autoridade e o poder na tomada de decisão são correlatos a quem detém o domínio da terra e/ou dos recursos naturais de um sítio protegido. A responsabilidade sobre a gestão de um sítio e a responsividade (transparência) variam conforme a democracia de um EstadoNação (BORRINI et al., 2013).

A Governança do Estado ocorre quando um órgão governamental detém o poder, a autoridade e a responsabilidade na gestão e na prestação de contas do sítio protegido. Nesse tipo de governança é o poder público quem determina os objetivos do sítio protegido, desenvolve e atualiza seu Plano de Manejo e possui o domínio da terra e/ou recursos naturais (GRAHAM; AMOS; PLUMPTRE, 2003; BORRINI et al., 2013).

Em alguns casos o Estado mantém o domínio da terra, o controle e a fiscalização das Áreas Protegidas, mas delega as atividades cotidianas de gestão para uma organização paraestatal, Organização Não Governamental (ONG), operador privado ou comunidade (GRAHAM; AMOS; PLUMPTRE, 2003; BORRINI et al., 2013). 
Sob a Governança do Estado, existem casos em que há ou não uma obrigação legal de informar ou consultar as partes interessadas (atores sociais), antes da criação de sítios, assim como da tomada de decisão sobre a gestão. Os níveis de responsabilização e prestação de contas variam de acordo com o nível de democracia de cada país (WORBOYS et al., 2015).

A Governança Compartilhada ocorre quando há mecanismos e processos institucionais empregados para compartilhar a autoridade e a responsabilidade entre uma pluralidade de atores governamentais e não-governamentais de forma formal ou informal. Por essa razão, a cogestão ocorre de muitas formas, por vezes "fracas" ou "fortes" (GRAHAM; AMOS; PLUMPTRE, 2003; BORRINI et al., 2013).

Nas formas fracas, ou "colaborativas", a autoridade e a responsabilidade na tomada de decisão são de um órgão governamental (Estado), mas esse órgão é obrigado, seja por força de Lei ou alguma política, a informar ou consultar as partes interessadas. Em formas mais fortes de "colaboração" existem órgãos colegiados multipartes, formados por atores sociais, que são responsáveis pelo desenvolvimento de propostas técnicas para a regulamentação e a gestão do sítio protegido. Todavia, na tomada de decisão, a autoridade e o poder plenos ainda são do Estado. Na gestão conjunta, ou seja, a forma mais forte de cogestão, atores sociais fazem parte da equipe do órgão gestor do sítio (WORBOYS et al., 2015).

A Governança Privada compreende sítios protegidos sob domínio da propriedade privada, seja ela individual, cooperativa, ONG ou corporativa, com fins lucrativos ou não (GRAHAM; AMOS; PLUMPTRE, 2003; BORRINI et al., 2013).

Os sítios sob Governança Privada sem fins lucrativos normalmente estão relacionados: a) às áreas adquiridas por ONGs explicitamente para fins de proteção ambiental; b) às áreas onde o proprietário (s) por um valor simbólico, sagrado e/ou imaterial, que deseja manter o ambiente ou seus recursos naturais protegidos (ou, um elemento específico) (GRAHAM; AMOS; PLUMPTRE, 2003; BORRINI et al., 2013).

$\mathrm{Na}$ Governança Privada o poder, a autoridade e a responsabilidade cabem ao proprietário. São eles que fazem a gestão, controlam a terra e os recursos naturais, determinam os objetivos de proteção ambiental, desenvolvem e cumprem os Planos de Manejo e são responsáveis pela tomada de decisão. Nesse tipo de governança, cabe ao poder público (Estado) fiscalizar o sítio protegido de acordo com a Lei do país. A prestação de contas em relação à sociedade, 
geralmente, é bastante limitada. Algumas formas de prestação de contas podem ser negociadas com o governo em troca de incentivos específicos. A transparência da informação é somente obrigatória junto aos órgãos executores ambientais (WORBOYS et al., 2015).

A Governança Comunitária ocorre quando o ambiente é voluntariamente protegido pelas comunidades tradicionais, por meio de leis consuetudinárias ou outros meios efetivos. Na Governança Comunitária o poder, a autoridade e a responsabilidade são das comunidades tradicionais, por meio de uma variedade de formas de governança étnica ou de acordos e regras de organizações locais. As formas de governança e suas regras de organização são adaptadas ao contexto específico de aplicação e podem ser extremamente diversas e sofisticadas (GRAHAM; AMOS; PLUMPTRE, 2003; BORRINI et al., 2013).

As decisões de gestão são voluntárias e os esforços de tais comunidades conduzem à proteção ambiental e garantia dos valores culturais a ela associados. Nesse caso, o status de área protegida pode ser configurado para atender a uma variedade de objetivos, além dos relacionados à proteção ambiental (BORRINI et al., 2013).

A Governança Comunitária surgiu dos anseios de alguns povos indígenas e comunidades tradicionais que estão "preocupados" com os ecossistemas relevantes, usualmente relacionados a eles culturalmente, religiosamente e/ou como meio de subsistência. A tomada de decisão sobre a gestão dos ecossistemas em jogo, implica na existência de alguma forma de autoridade comunitária que é capaz de impor regulamentos (BORRINI et al., 2013).

$\mathrm{Na}$ Governança Comunitária, a terra e/ou os recursos naturais podem ser de domínio, posse ou gestão coletivos, individual ou de acordo com um grupo ou família. As regras de organização geralmente variam conforme valores e práticas culturais ou religiosas. $\mathrm{Na}$ maioria das vezes, as regras responsáveis pela gestão de um sítio com Governança Comunitária não possuem sanção legal pelo Estado. A autoridade, o poder de decisão e a responsabilidade devem ser plenamente e reconhecidamente das comunidades tradicionais (GRAHAM; AMOS; PLUMPTRE, 2003; BORRINI et al., 2013).

A responsabilidade da comunidade em relação à sociedade na Governança Comunitária é limitada. Porém, ela pode ser aprimorada e concretizada por meio de negociações, o que às vezes resulta em acordos de gestão com outras partes interessadas (WORBOYS et al., 2015).

De acordo com Borrini et al. (2013), os tipos de governança devem ser neutros entre as categorias do SIAP da IUCN, ou seja, não existe predeterminação 
de um tipo de governança para uma categoria de área protegida. Assim, no SIAP da IUCN existem categorias de áreas protegidas que preenchem cada combinação possível de tipo de governança (WORBOYS et al., 2015).

Além disso, o SIAP da IUCN recomenda aos SNAPs que todas as categorias de áreas protegidas possam ser de qualquer domínio da terra e/ou dos recursos naturais, independentemente do nível de restrição da proteção ambiental - p. ex.: um Parque Nacional pode ser de propriedade (domínio) de agências governamentais, ONGs, comunidades, povos indígenas, empresas e proprietários particulares, isoladamente ou em combinação (BORRINI et al., 2008).

Harmon (2008) alerta que somente nessas condições, um SNAP pode ser totalmente funcional ou pleno. Segundo Mulongoy e Chape (2004), os SNAPs que não atuam em sua plenitude acabam tendo como base modelos de gestão que excluem comunidades locais e tradicionais por perceberem que a existência delas, suas visões de mundo, modos de vida e atividades são incompatíveis com a proteção ambiental. De acordo com os autores, isso pode vir a ocorrer até mesmo em sítios que foram concebidos para incluírem populações humanas em seu interior.

\section{UM PANORAMA DA GOVERNANÇA EM UNIDADES DE CONSERVAÇÃO DA NATUREZA}

O SNUC foi concebido por meio de Lei no Brasil para nortear a criação, implantação e gestão de UC. Nele constam princípios, diretrizes, objetivos, determinações e instrumentos para a gestão de sítios protegidos no país. O SNUC prevê, em geral, duas concepções de relação homem e natureza, a preservação e a conservação, sendo a sua proteção, um conceito "guarda-chuva".

Para o SNUC, a preservação ambiental envolve um "conjunto de métodos, procedimentos e políticas que visem a proteção a longo prazo das espécies, habitats e ecossistemas, além da manutenção dos processos ecológicos, prevenindo a simplificação dos sistemas naturais" (BRASIL, 2000, Art. 2, V).

Enquanto, a conservação ambiental é:

O manejo do uso humano da natureza, compreendendo a preservação, a manutenção, a utilização sustentável, a restauração e a recuperação do ambiente natural, para que possa produzir o maior benefício, em bases sustentáveis, às atuais gerações, mantendo seu potencial de satisfazer as necessidades e aspirações das gerações futuras, e garantindo a sobrevivência dos seres vivos em geral (BRASIL, 2000, Art. 2, II.). 
Com base nesses dois conceitos, o SNUC separa as categorias de manejo de UC (tipos) em dois grupos: Proteção Integral e Uso Sustentável. A grande diferença entre as UC do grupo de Proteção Integral e as do grupo de Uso Sustentável envolve o uso dos recursos naturais.

Nas UC do grupo de Proteção Integral somente são permitidos os usos indiretos dos recursos naturais, ou seja, aqueles que não envolvem consumo, coleta, dano ou destruição dos recursos naturais (BRASIL, 2000, Art. $2^{\circ}$, IX).

Segundo o SNUC, Lei n. 9.985 de 2000 (BRASIL, 2000), dentre as categorias de manejo do grupo de Unidades Proteção Integral tem-se:

Estação Ecológica (ESEC): categoria de manejo destinada à preservação da natureza e a pesquisa científica (Art. $9^{\circ}$ ). A intervenção humana direta somente poderá se dar na forma de medidas de restauração de ecossistemas, manejo de espécies para preservar a biodiversidade e pesquisa científica controlada (Art. $9^{\circ}, \sqrt{ } 4^{\circ}$, I, II, III e IV). A visitação pública somente é permitida com o objetivo educacional (Art. $9^{\circ}, \int 4^{\circ}$ ). O domínio é público e áreas particulares devem ser desapropriadas $\left(\right.$ Art. $\left.9^{\circ}, \int 1^{\circ}\right)$. A governança é sempre do estado que pode delegá-la a uma Organização de Sociedade Civil de Interesse Público (OSCIP) ou compartilhá-la (Art. 29 e 30).

Reserva Biológica (REBIO): categoria de manejo destinada à preservação da biodiversidade e dos demais atributos naturais existentes em seus limites cartográficos (Art. 10). A intervenção humana direta somente poderá darse na forma de medidas recuperação de ecossistemas, pesquisa científica e as ações de manejo necessárias para recuperar e preservar o equilíbrio natural, a biodiversidade e os processos ecológicos naturais (Art. 10). A visitação pública somente é permitida com o objetivo educacional (Art. 10, \ $2^{\circ}$ ). O domínio é público e áreas particulares devem ser desapropriadas (Art. 10, \ $1^{\circ}$ ). Governança é sempre do estado que pode delegá-la à uma Organização de Sociedade Civil de Interesse Público (OSCIP) ou compartilhá-la (Art. 29 e 30).

Parque Nacional (PARNA) e suas variantes estadual e natural municipal: categoria de manejo destinada à preservação dos ecossistemas naturais de grande relevância ecológica e beleza cênica (Art. 11). Nele se permite o desenvolvimento de atividades recreativas, de turismo ecológico, educativas e de interpretação ambiental, além de permitir a realização de pesquisas científicas e medidas de restauração e recuperação de ecossistemas (Art. 11). O domínio é público e áreas particulares devem ser desapropriadas (Art. 11, $\mathbb{\int} 1^{\circ}$ ). Governança é sempre do 
estado que pode incube-la a uma Organização de Sociedade Civil de Interesse Público (OSCIP) ou compartilhá-la (Art. 29 e 30).

Monumento Natural (MONA): categoria de manejo destinada à preservação de sítios naturais singulares, raros e de grande beleza cênica, como, por exemplo, as formações geológicas (Art. 12). A visitação e pesquisa científicas são permitidas conforme restrições do sítio (Art. 12, \ $3^{\circ}$ ). Pode ser constituída de áreas particulares, desde que as atividades realizadas nessas áreas sejam compatíveis com os objetivos da UC (Art. 12, \ $1^{\circ}$ ). Em caso contrário deverá haver desapropriação (Art. 12, \ $2^{\circ}$ ). Governança é sempre do estado que pode delegá-la a uma Organização de Sociedade Civil de Interesse Público (OSCIP) ou compartilhá-la (Art. 29 e 30).

Refúgio da Vida Silvestre (RVS): categoria de manejo destinada à proteção de ambientes naturais com objetivo de assegurar condições para a existência ou reprodução de espécies ou comunidades da flora e da fauna (Art. 13). A visitação e pesquisas científicas são permitidas conforme restrições do sítio (Art. 13, S $\left.3^{\circ}\right)$. Pode ser constituída de áreas particulares, desde que as atividades realizadas nessas áreas sejam compatíveis com os objetivos da UC (Art. 13, \ 1º). Em caso contrário deverá haver desapropriação (Art. 13, \2 $2^{\circ}$ ), governança é sempre do estado que pode delegá-la a uma Organização de Sociedade Civil de Interesse Público (OSCIP) ou compartilhá-la (Art. 29 e 30).

Todas as UC do Grupo de Proteção Integral devem possuir um Conselho Gestor consultivo, criado por meio de ato legal. O Conselho também deverá ter ato legal (Lei, Decreto ou Portaria) de: (i) nomeação das instituições que o compõem; (ii) indicação ou de aprovação da eleição dos representantes com assento no Conselho; e (iii) termo de posse dos conselheiros. O Conselho Gestor deve elaborar e aprovar um Regimento Interno que deverá ser regulamentado e atualizado (BRASIL, 2000, 2002, 2014; ICMBIO, 2019).

As UC do grupo de Uso Sustentável permitem os usos diretos dos recursos naturais, ou seja, aqueles que envolvem coleta e uso, comercial ou não, dos recursos naturais (BRASIL, 2000, Art. $2^{\circ}, \mathrm{X}$ ), desde que se compatibilize a "conservação da natureza com o uso sustentável de parcela dos seus recursos naturais" (BRASIL, 2000, Art. $7^{\circ}, \mathrm{II}, \$ 2^{\circ}$ ).

Segundo o SNUC, Lei n. 9.985 de 2000 (BRASIL, 2000), dentre as categorias de manejo do grupo de Unidades de Uso Sustentável tem-se: 
Área de Proteção Ambiental (APA): categoria de manejo dotada de atributos naturais, estéticos e culturais importantes para a qualidade de vida e o bem-estar das populações humanas. Geralmente, o sítio possui uma área extensa, com o objetivo de proteger a diversidade biológica, ordenar o processo de ocupação humana e assegurar a sustentabilidade do uso dos recursos naturais (Art. 15). Ela pode ser constituída por terras públicas e privadas (Art. 15, \ $1^{\circ}$ ). O uso dos recursos naturais, a ocupação humana, a visitação e a pesquisa científicas são permitidas conforme restrições do sítio. Nas áreas públicas é de controle do órgão gestor e nos particulares cabe ao poder público fiscalizar (Art. 13, \ $1^{\circ}, 2^{\circ}$, $3^{\circ}$ e $4^{\circ}$ ). A APA deverá dispor de um Conselho Gestor (Art. 13, \5 $5^{\circ}$, Art. 32, \ $\left.2^{\circ}\right)$. A governança é do estado com a possibilidade de delegá-la ou compartilhála, uma vez que a presidência do Conselho é exclusiva do órgão gestor da UC.

Área de Relevante Interesse Ecológico (ARIE): categoria de manejo de pequena extensão, com pouca ou nenhuma ocupação humana e com características naturais extraordinárias ou que abriga exemplares raros da biota regional. Possui o objetivo de manter os ecossistemas naturais de importância regional ou local e regular o uso dos recursos naturais, de forma que os compatibilize com os objetivos da unidade (Art. 16). Pode ser constituída por terras públicas e privadas (Art. 16, $\int 1^{\circ}$ ). O uso da propriedade privada é regulado pelas restrições do sítio (Art. 16, \ $2^{\circ}$ ). Não há menção no SNUC sobre a visitação e a pesquisa pública em sítios dessa categoria, mas também não há vedação. No caso de áreas particulares a visitação e a pesquisa devem constar nas restrições do sítio. Não há menção no SNUC de necessidade de Conselho Gestor para ARIEs. Dessa forma, a governança é exclusiva do estado.

Floresta Nacional (FLONA) e suas variantes estadual e municipal: categoria de manejo com cobertura florestal onde predominam espécies nativas. Visa o uso múltiplo sustentável dos recursos florestais e a pesquisa científica, com ênfase em métodos para exploração sustentável de florestas nativas (Art. 17). O domínio é público e as áreas particulares devem ser desapropriadas (Art. 17, 』 $\left.1^{\circ}\right)$. É admitida a permanência de populações tradicionais que a habitam desde sua criação (Art. 16, $\int 2^{\circ}$; Art. 23) de acordo o estabelecimento de Termo de Concessão (Art. 18, \ 1 ${ }^{\circ}$; Art. 23) ou Contrato de Concessão de Direito Real de Uso - CCDRU). A visitação e a pesquisa pública são permitidas conforme as restrições do sítio. (BRASIL, 1967, 1988, 2000, 2007) A FLONA deverá dispor de um Conselho Gestor Consultivo (Art. 16, $\int 5^{\circ}$ ). A governança é do estado 
com a possibilidade de delegá-la ou compartilhá-la, uma vez que a presidência do Conselho é exclusiva do órgão gestor da UC.

Reserva Extrativista (RESEX): categoria de manejo onde há uma área natural utilizada por comunidades extrativistas tradicionais que exercem suas atividades baseadas no extrativismo, na agricultura de subsistência e na criação de animais de pequeno porte. O objetivo é compatibilizar o uso tradicional sustentável dos recursos naturais existentes e a proteção dos meios de vida e da cultura dessas populações (Art. 18). Permite a visitação pública compatível aos modos de vidas dos tradicionais (Art. 18, $\int 3^{\circ}$ ) e a pesquisa científica, conforme as restrições do órgão gestor (Art. $18, \int 4^{\circ}$ ). O domínio é público e as áreas particulares devem ser desapropriadas (Art. 18, $₫ 1^{\circ}$ ). Às comunidades tradicionais são permitidas a moradia e uso dos recursos naturais por meio de Termo de Concessão (Art. 18, \ 1º; Art. 23) ou CCDRU (BRASIL, 1967, 1988, 2000, 2007). A RESEX deverá dispor de um Conselho Gestor deliberativo (Art. 18, \20\% . A governança é do estado com a possibilidade de delegá-la ou compartilhá-la, uma vez que a presidência do Conselho é exclusiva do órgão gestor da UC.

Reserva de Fauna (REFAU): categoria de manejo onde há uma área natural com populações animais de espécies nativas, terrestres ou aquáticas. Tem como objetivo a realização de estudos técnico-científicos sobre o manejo econômico sustentável de recursos faunísticos (Art. 19). Permite a visitação pública conforme restrições do órgão gestor (Art. 19, \ $2^{\circ}$ ). O domínio é público e as áreas particulares devem ser desapropriadas (Art. 19, \ $1^{\circ}$ ). Não há menção no SNUC de necessidade de Conselho Gestor para ARIEs. Dessa forma, a governança é exclusiva do estado.

Reserva de Desenvolvimento Sustentável (RDS): categoria de manejo onde há uma área natural que abriga comunidades tradicionais. Estes tradicionais devem usar sistemas sustentáveis de exploração de recursos naturais desenvolvidos ao longo de gerações e adaptados às condições ecológicas locais (Art. 20). Tem como objetivo preservar a natureza e assegurar as condições e os meios necessários para a reprodução e a melhoria dos modos de vida e atividades dos tradicionais, bem como valorizar, conservar e aperfeiçoar seus conhecimentos e técnicas de manejo do ambiente (Art. 20, $\sqrt{ } 1^{\circ}$ ). Permite visitação pública desde que compatível com os interesses das comunidades tradicionais e restrições do sítio (Art. 20, \5 $5^{\circ}$, I). Permite a pesquisa científica, principalmente correlata aos modos de vida e atividades dos tradicionais, conforme restrições do sítio (Art. 20, \5\%, II). O 
domínio é público e as áreas particulares devem ser desapropriadas (Art. 20, \$ $2^{\circ}$ ). Às comunidades tradicionais são permitidas a moradia e uso dos recursos naturais por meio de Termo de Concessão (Art. 23) ou CCDRU (BRASIL, 1967, 1988, 2000, 2007). A RDS deverá dispor de um Conselho Gestor deliberativo (Art. $20, \mathbb{S} 4^{\circ}$ ) A governança é do estado com a possibilidade de delegá-la ou compartilhá-la, uma vez que a presidência do Conselho é exclusiva do órgão gestor da UC.

Reserva Particular do Patrimônio Natural (RPPN): única categoria de manejo com domínio exclusivo da propriedade privada, consequentemente a autoridade e responsabilidade na gestão é exclusiva do (s) proprietário (s) (Art. 21). É gravada como UC com perpetuidade em Termo de Compromisso (Art. 21, $\int 1^{\circ}$ ). Têm como objetivo conservar a biodiversidade (Art. 21). Permite a pesquisa científica e a visitação turística, recreativa e educacional (Art. 21, $\ 2^{\circ}$, I e II), conforme Plano de Manejo. Não há menção no SNUC de necessidade de Conselho Gestor para RPPNs. Dessa forma, a governança é exclusivamente privada.

\section{AS CATEgorias DE UNIDADES DE CONSERVAÇÃO DA NATUREZA E SEUS TIPOS DE GOVERNANÇA - UMA ANÁLISE DO SNUC E DO DECRETO No $4.340 / 2002$}

No item anterior viu-se que, no caso brasileiro, o SNUC e o Decreto ${ }^{\circ}$ 4.340/2002 são o principal marco legal da governança em UC no Brasil, pois neles se determina o tipo de governança para cada categoria de manejo. Além disso, os dois regulamentos também determinam quem detém o domínio, o poder na tomada de decisão, a autoridade, a responsabilidade e a responsividade (transparência). Ainda eles fornecem os princípios, diretrizes, objetivos e instrumentos para realização da governança em UC.

Neste contexto, sistematizou-se no Quadro 1 os dados da leitura crítica do SNUC e do Decreto $n^{\circ} 4.340 / 2002$ promovida para verificar se as duas políticas públicas permitem que cada categoria de UC e seus sítios possam exercer todas as possibilidades de domínio da terra e/ou dos recursos naturais, conforme recomendação do SIAP da IUCN. 
Quadro 1 - O domínio da terra e/ou dos recursos naturais de cada categoria de manejo do SNUC.

\begin{tabular}{|c|c|c|c|c|c|c|}
\hline Grupo & $\begin{array}{c}\text { Categoria de } \\
\text { Manejo/ Posse e } \\
\text { domínio }\end{array}$ & $\begin{array}{c}\text { Fede- } \\
\text { ral }\end{array}$ & $\begin{array}{l}\text { Esta- } \\
\text { dual }\end{array}$ & $\begin{array}{l}\text { Munici- } \\
\text { pal }\end{array}$ & $\begin{array}{l}\text { Proprieda- } \\
\text { de Privada }\end{array}$ & $\begin{array}{l}\text { Comunida- } \\
\text { des tradi- } \\
\text { cionais }\end{array}$ \\
\hline \multirow{5}{*}{$\begin{array}{l}\text { Proteção } \\
\text { Integral }\end{array}$} & $\begin{array}{c}\text { Estação Ecológica } \\
\text { (ESEC) }\end{array}$ & & & & & \\
\hline & $\begin{array}{l}\text { Reserva Biológica } \\
\text { (REBIO) }\end{array}$ & & & & & \\
\hline & $\begin{array}{l}\text { Parque Nacional } \\
\text { (PARNA) }\end{array}$ & & & & & \\
\hline & $\begin{array}{c}\text { Monumento } \\
\text { Natural (MONA) }\end{array}$ & & & & & \\
\hline & $\begin{array}{c}\text { Reserva de Vida } \\
\text { Silvestre (RVS) }\end{array}$ & & & & & \\
\hline \multirow{7}{*}{$\begin{array}{l}\text { Uso Sus- } \\
\text { tentável }\end{array}$} & $\begin{array}{l}\text { Área de Proteção } \\
\text { Ambiental (APA) }\end{array}$ & & & & & \\
\hline & $\begin{array}{c}\text { Área de Relevante } \\
\text { Interesse Ecológico } \\
\text { (ARIE) }\end{array}$ & & & & & \\
\hline & $\begin{array}{l}\text { Floresta Nacional } \\
\text { (FLONA) }\end{array}$ & & & & & \\
\hline & $\begin{array}{c}\text { Reserva Extrativista } \\
\text { (RESEX) }\end{array}$ & & & & & \\
\hline & $\begin{array}{l}\text { Reserva de Fauna } \\
\text { (REFAU) }\end{array}$ & & & & & \\
\hline & $\begin{array}{c}\text { Reserva de } \\
\text { Desenvolvimento } \\
\text { Sustentável (RDS) }\end{array}$ & & & & & \\
\hline & $\begin{array}{c}\text { Reserva Particular } \\
\text { do Patrimônio } \\
\text { Natural (RPPN) }\end{array}$ & & & & & \\
\hline
\end{tabular}

Fonte: Elaborado pelos autores (2019) com base nas determinações do SNUC e seu Decreto no 4.340/2002 (BRASIL, 2002).

Legenda: sombreamento indica a possibilidade de domínio na categoria de manejo.

Com base no Quadro 1, nota-se que 11 categorias de manejo, excetuandose a RPPN, são de domínio do Estado, sendo que em cinco delas pode haver terras de domínio particular, conforme condições especificadas no SNUC. No Brasil, nos casos em que há domínio exclusivo do Estado e existem propriedades particulares, deverá obrigatoriamente após a criação do sítio protegido haver desapropriação, indenização e/ou realocação de populações.

A MONA, RVS e RDS preveem a possibilidade de o sítio coexistir com o domínio particular desde que o uso e acesso aos recursos naturais e a ocupação 
humana estejam de acordo com a Lei, com o Plano de Manejo, o Zoneamento Ambiental e as restrições do sítio. Caso a coexistência seja inviável obrigatoriamente deverá haver desapropriação, indenização e/ou realocação de populações.

A ARIE e APA possibilitam a existência de terras de domínio particular no interior de seus sítios, sendo que o controle do uso e acesso aos recursos naturais, e da ocupação humana são de responsabilidade do proprietário. Nesse caso, as propriedades particulares em ARIEs e APAs estão sobre as restrições impostas pela Lei, o Plano de Manejo, o Zoneamento Ambiental e as restrições do sítio, cabendo ao poder público fiscalizá-las. As APAs e ARIES são as únicas categorias de manejo onde há domínio público e/ou privado sem exigir a priori desapropriação, ou seja, a terra privada não necessita obrigatoriamente ser desapropriada, da criação da UC ou caso não siga as determinações do Plano de Manejo e outros regulamentos legais, conforme descreve o SNUC.

Nas FLONAs e RESEXs o domínio é exclusivo do Estado, devendo haver desapropriação, indenização e/ou realocação de populações. Todavia, nos sítios dessas categorias de manejo é permitida a permanência das comunidades tradicionais sob regime de concessão por meio do firmamento de um contrato. Assim, por meio do SNUC, nas FLONAs e RESEX se reconhece a posse ou direito histórico de tradicionais por meio de um contrato de concessão. Em áreas de domínio público nas RDS também pode ser firmado um contrato de cessão, tal como nas FLONAs e RESEXs.

O arcabouço legal brasileiro somente reconhece dois tipos de domínio, o público e o privado. A posse ou direito histórico de uma comunidade tradicional não são reconhecidos por Lei. O direito de uma comunidade tradicional só é reconhecido via contrato de concessão (CCDRU) ou, em alguns casos, por Termos de Ajustamento de Conduta (TAC) ou Termo de Compromisso, sendo o domínio ainda do poder público. Assim, os posseiros e tradicionais não são passíveis de desapropriação.

A RPPN é de domínio particular e, por isso, o uso e acesso aos recursos naturais e a ocupação humana são de responsabilidade do proprietário. Este deverá seguir a Lei e elaborar o Plano de Manejo, o Zoneamento Ambiental e as restrições do sítio. Cabe ao poder público fiscalizar as ações dos proprietários de RPPNs.

Ainda, com base no Quadro 1 evidencia-se que no SNUC, o domínio da terra e dos recursos naturais não é neutro entre as categorias de manejo como no SIAP da IUCN. Nele, as categorias de manejo não possuem a possibilidade de ter todos os tipos de domínio. Com isso, o Brasil não segue a recomendação da IUCN de preencher cada combinação possível de tipo de domínio para cada categoria de UC. 
No Quadro 2 sistematizou-se os dados da leitura crítica do SNUC e do Decreto $\mathrm{n}^{\circ} 4.340 / 2002$ promovida no item anterior para verificar se as duas políticas públicas permitem que cada categoria de UC e seus sítios possam exercer todas as possibilidades da dimensão tipo de governança, conforme recomendação do SIAP da IUCN.

Quadro 2 - Tipos de governança de cada categoria de manejo de UC do SNUC.

\begin{tabular}{|c|c|c|c|c|c|c|c|c|}
\hline \multirow{2}{*}{$\begin{array}{c}\text { Tipos de } \\
\text { governança/ } \\
\text { Categoria de } \\
\text { Manejo }\end{array}$} & \multicolumn{4}{|c|}{$\begin{array}{c}\text { Governança do } \\
\text { Estado }\end{array}$} & \multicolumn{2}{|c|}{$\begin{array}{c}\text { Governança } \\
\text { Compartilhada } \\
\text { (cogestão) }\end{array}$} & \multirow{2}{*}{ 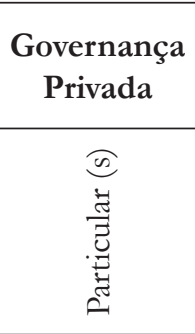 } & \multirow{2}{*}{ 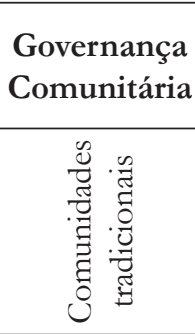 } \\
\hline & 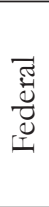 & 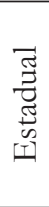 & 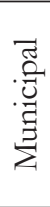 & 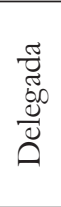 & 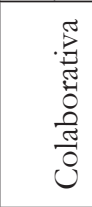 & 鹃 & & \\
\hline \multicolumn{9}{|l|}{ ESEC } \\
\hline \multicolumn{9}{|l|}{ REBIO } \\
\hline \multicolumn{9}{|l|}{ PARNA } \\
\hline \multicolumn{9}{|l|}{ MONA } \\
\hline \multicolumn{9}{|l|}{ RVS } \\
\hline \multicolumn{9}{|l|}{ APA } \\
\hline \multicolumn{9}{|l|}{ ARIE } \\
\hline \multicolumn{9}{|l|}{ FLONA } \\
\hline \multicolumn{9}{|l|}{ RESEX } \\
\hline \multicolumn{9}{|l|}{ REFAU } \\
\hline \multicolumn{9}{|l|}{ RDS } \\
\hline RPPN & & & & & & & & \\
\hline
\end{tabular}

Fonte: Elaborado pelos autores (2019) com base nas determinações do SNUC e do Decreto $n^{\circ} 4.340 / 2002$ (BRASIL, 2002).

Legenda: sombreamento indica a possibilidade de tipo de governança na categoria de manejo.

Com base no Quadro 2, nota-se que 11 categorias de manejo, excetuandose a RPPN podem exercer a governança do Estado, sendo possível a delegação da gestão por meio de uma OSCIP. Na governança do Estado, o poder, a autoridade, a responsabilidade e a responsividade são do poder público.

A Governança Compartilhada pode existir em oito das 11 categorias de manejo, excetuando-se a RPPN, a ARIE e a REFAU. Na ARIE e na REFAU, o SNUC não faz nenhuma menção à existência de Conselhos Gestores. Consequentemente, não existe possibilidade de Gestão Compartilhada.

As formas fracas e fortes de colaboração na Gestão Compartilhada dependem do tipo de Conselho Gestordecada categoria de manejo. Nos Conselhos 
Gestores consultivos (forma fraca), o poder, a autoridade e a responsabilidade são do órgão governamental (Estado), mas esse órgão é obrigado pelo SNUC a informar ou consultar as partes interessadas (conselheiros). Nos deliberativos (forma forte), o órgão colegiado é multiparte, ou seja, formado por atores sociais responsáveis pelo desenvolvimento de propostas técnicas para a regulamentação e gestão do sítio. O poder na tomada de decisão, a autoridade, a responsabilidade e responsividade são compartilhados entre o Estado e o Conselho.

O Quadro 3 evidencia a predeterminação do tipo de Conselho Gestor para cada categoria de manejo do SNUC.

Quadro 3 - Tipos de Conselho Gestor de cada categoria de manejo de UC do SNUC.

\begin{tabular}{|c|c|l|l|}
\hline \multirow{4}{*}{ Grupo } & Conselho gestor/Categoria de UC & Consultivo & Deliberativo \\
\hline \multirow{4}{*}{$\begin{array}{c}\text { Proteção } \\
\text { Integral }\end{array}$} & ESEC & & \\
\cline { 2 - 4 } & REBIO & & \\
\cline { 2 - 4 } & PARNA & & \\
\hline & MONA & & \\
\hline & RVS & & \\
\cline { 2 - 4 } & APA & & \\
\cline { 2 - 4 } Uso & ARIE & & \\
\cline { 2 - 4 } & RLONA & & \\
\cline { 2 - 4 } & RESEX & & \\
\cline { 2 - 4 } & REFAU & & \\
\cline { 2 - 4 } & RDS & & \\
\hline
\end{tabular}

Fonte: Elaborado pelos autores (2019) com base no SNUC e seu Decreto no 4.340/2002 (BRASIL, 2002).

Com base no Quadro 3, percebe-se que o SNUC prevê para as categorias de manejo do grupo de Proteção Integral a governança na forma de Conselhos Gestores consultivos. Assim, nas UC de Proteção Integral só é possível uma Governança Compartilhada colaborativa fraca. O mesmo ocorre na categoria de manejo FLONA, do grupo de Uso Sustentável, pois nela somente é previsto o Conselho Gestor consultivo. Já na RDS, APA e RESEX é previsto pelo SNUC o Conselho Gestor Deliberativo. Por isso, nessas categorias de manejo é possível uma governança Compartilhada colaborativa forte.

No caso específico das RESEX e RDS, as comunidades tradicionais participam do Conselho Gestor deliberativo. Elas não detêm o domínio da terra nem dos recursos naturais e, por isso, não possuem poder e autoridade plenas do sítio, sendo essa partilhada por meio do Conselho com o Estado. A posse e o uso 
dessas comunidades tradicionais são reconhecidos e regulados pela concessão. Como o domínio da terra não pertence a esses coletivos, a proteção ambiental não pode ser executada por meio de suas leis consuetudinárias, a não ser que elas estejam sob a forma de acordos voluntários constantes no contrato de concessão.

A Governança Compartilhada de nível Conjunta também não é possível de ser executada conforme as determinações do SNUC. Nessa forma de governança, vários atores locais devem ocupar a estrutura administrativa do órgão gestor de UC, ou seja, a equipe gestora da unidade. O Sistema somente prevê a participação, em alguns casos, em Conselhos Gestores deliberativos, porém esses não detêm o poder e a autoridade plenas, essa pertencente somente ao Estado. A Governança Privada no SNUC somente é possível na RPPN.

Assim, com base nos Quadro 2 e 3, evidencia-se que no SNUC, os tipos de governança não são neutros entre as categorias de manejo como no SIAP da IUCN. No SNUC, as categorias de manejo não possuem a possibilidade de exercer todos os tipos de governança. Com isso, o Brasil não segue a recomendação da IUCN de preencher cada combinação possível de tipo de governança para cada categoria de UC. Esse fato, junto à predeterminação do domínio, torna o SNUC um SNAP não pleno, conforme indica Harmon (2008). Esse cenário, segundo Cozzolino $(2005,2014)$, é passível de promover ou intensificar conflitos, principalmente no tocante às comunidades locais e tradicionais.

Segundo Mulongoy e Chape (2004), os SNAPs que não atuam em sua plenitude acabam tendo como base modelos de gestão que excluem comunidades locais e tradicionais por perceberem que elas, suas visões de mundo, modos de vida e atividades, são incompatíveis com a proteção ambiental. De acordo com os autores, isso pode vir a ocorrer até mesmo em sítios que foram concebidos para incluir populações humanas em seu interior.

\section{CONSIDERAÇÕES FINAIS}

Neste trabalho evidenciou-se que no SNUC, o domínio da terra e/ou dos recursos naturais não é neutro entre as categorias de manejo de UC, assim como as categorias de manejo de UC não possuem a possibilidade de exercer todos os tipos de governança de áreas protegidas. Com isso, o Brasil, não segue a recomendação do SIAP da IUCN de preencher cada combinação possível de tipo de governança de área protegida e de domínio, o que torna o SNUC um SNAP não pleno e, com isso, passível de excluir comunidades locais e tradicionais do seu interior e da gestão de seus sítios e promover conflitos. 
No Brasil, somente a propriedade pública e particular são reconhecidas por Lei. A posse ou direito de uso histórico de uma comunidade tradicional não são reconhecidos na forma de domínio. Ou seja, o domínio, a autoridade, o poder e a responsabilidade perante as áreas das comunidades tradicionais no interior de uma UC são do poder público.

Com isso ocorrem duas coisas:

i) Não é possível a desapropriação de terras durante a criação de uma UC de domínio do Estado, pois não existe título de propriedade dessas comunidades tradicionais, ou seja, essas pessoas não podem ser indenizadas ou realocadas caso elas não sejam mantidas nas suas posses ou áreas de uso históricas pelo poder público. Afora isso, o processo de desapropriação somente abarca a questão da propriedade e da moradia. Os regimes de apropriação dos recursos naturais, diretos e indiretos, e as inter-relações estabelecidas entre o homem e o ambiente são ignorados por ele, o que leva esse instrumento a negar a posse e os direitos hereditário, tradicional ou consuetudinários.

ii) A posse ou direito de uso histórico de uma comunidade tradicional somente podem vir a ser reconhecidos parcialmente, via cessão, em sítios das categorias de manejo RESEX, RDS e FLONA. O domínio continua sendo do Estado, com isso, a autoridade, o poder e a responsabilidade também. Atenta-se que autoridade, o poder e a responsabilidade podem ser compartilhados pelo poder público com essas comunidades.

Assim sendo, o SNUC torna inviável a concretização da governança pela Comunidade e, se ela ocorrer, será extraoficialmente e um movimento contra o Sistema. Já que para ocorrer esse tipo de governança deve-se haver o domínio da terra e dos recursos naturais pela (s)comunidade (s) tradicional (ais) que, com isso, adquirem autoridade e poder plenos sob suas áreas, consequentemente, sob a UC. A negação do direito a posse e os direitos hereditário, tradicional ou consuetudinário costumam ocasionar diversos conflitos em UC e áreas protegidas.

O SNUC e o Decreto $\mathrm{n}^{\circ}$. 4.340/2002 também possuem uma lacuna quanto à possibilidade de Gestão Conjunta, onde membros ou lideranças da comunidade local fazem parte do órgão gestor. Caso tal fato ocorra, será por outras vias que não por determinação da Lei.

A RPPN é a única categoria de manejo de domínio exclusivamente particular e, por isso, o acesso aos recursos naturais e a ocupação humana são 
de responsabilidade do proprietário, cabendo ao poder público a fiscalização. Além disso, não se prevê para a RPPN a existência de Conselho Gestor, ou seja, a gestão compartilhada. Consequentemente, a Governança em uma RPPN é exclusivamente privada

O restante das categorias de manejo de UC só ocorrem na forma de Governança do Estado, que pode ter delegação ou ser compartilhada em algum nível, a exceção da ARIE e REFAU onde é exclusiva do Estado.

\section{REFERÊNCIAS}

BORRINI, G.; DUDLEY, N.; JAEGER, T; LASSEN, B.; BROOME, N. P.; PHILLIPS, A.; SANDWITH, T. Governance of protected areas: from understanding to action. IUCN, [S. l.], 2013. Disponível em: https://portals.iucn. org/library/sites/library/files/documents/PAG-020.pdf. Acesso em: 07 abr. 2019. BRASIL. Decreto-Lei n ${ }^{\circ} 289$ de 28 de fevereiro de 1967. Cria o Instituto Brasileiro do Desenvolvimento Florestal e dá outras providências. Diário Oficial [da] República Federativa do Brasil, Poder Executivo, Brasília, DF, 28 fev. 1967. Disponível em: https:// www.planalto.gov.br/ccivil_03/DecretoLei/1965-1988/Del0289.htm. Acesso em: 07 abr. 2019.

BRASIL. Constituição da República Federativa do Brasil. Diário Oficial [da] República Federativa do Brasil, Poder Executivo, Brasília, DF: Senado, 1988. 140 p. Disponível em https://www.planalto.gov.br/ccivil_03/constituicao/ constituicao.htm. Acesso em: 07 abr. 2019.

BRASIL. Lei Federal no 9.985, de 18 de julho de 2000. Regulamenta o Art. 225드. par. $1^{\circ}$, incisos I, II, III e VII da Constituição Federal, institui o Sistema Nacional de Unidades de Conservação da Natureza e dá outras providências. Diário Oficial [da] República Federativa do Brasil, Poder Executivo, Brasília, DF, 19 jul. 2000. Disponível em https:// www.planalto.gov.br/ccivil_03/leis/19985. htm. Acesso em: 07 abr. 2019.

BRASIL. Decreto Federal no 4.340 de 22 de agosto de 2002. Regulamenta artigos da Lei $n^{\circ}$ 9.985, de 18 de julho de 2000, que dispõe sobre o Sistema Nacional de Unidades de Conservação da Natureza - SNUC, e dá outras providências. Diário Oficial [da] República Federativa do Brasil, Poder Executivo, Brasília, DF, 23 ago. 2002. Disponível em https:// www.planalto.gov.br/ccivil_03/ decreto/2002/d4340.htm. Acesso em: 07 abr. 2019. 
BRASIL. Lei no 11.481 de 31 de maio de 2007. Dá nova redação a dispositivos das Leis $\mathrm{n}^{\text {os }}$ 9.636, de 15 de maio de 1998, 8.666, de 21 de junho de 1993, 11.124, de 16 de junho de 2005, 10.406, de 10 de janeiro de 2002 - Código Civil, 9.514, de 20 de novembro de 1997, e 6.015, de 31 de dezembro de 1973, e dos DecretosLeis $\mathrm{n}^{\underline{\mathrm{os}}} 9.760$, de 5 de setembro de 1946, 271, de 28 de fevereiro de 1967, 1.876, de 15 de julho de 1981, e 2.398, de 21 de dezembro de 1987; prevê medidas voltadas à regularização fundiária de interesse social em imóveis da União; e dá outras providências. Diário Oficial [da] República Federativa do Brasil, Poder Executivo, Brasília, DF, 31 maio. 2007. Disponível em https:// www.planalto.gov.br/ccivil_03/_Ato2007-2010/2007/Lei/L11481.htm. Acesso em: 07 abr. 2019.

BRASIL. Instrução Normativa ICMBio n. 09 de 05 de dezembro de 2014. Disciplina as diretrizes, normas e procedimentos para formação, implementação e modificação na composição de Conselhos Gestores de Unidades de Conservação Federais. Diário Oficial [da] República Federativa do Brasil, Poder Executivo, Brasília, DF, 12 dez. 2014. Disponível em https:/ /www.icmbio. gov.br/cepsul/images/stories/legislacao/Instrucao_normativa/2014/in_ icmbio_09_2014_diretrizes_modifica $\%$ C3\%A7\%C3\%A3o_conselhos_gestores_ und_conserva $\%$ C3\%A7\%C3\%A3o_federais.pdf. Acesso em: 07 abr. 2019.

COZZOLINO, L. F. F. Unidades de Conservação e os processos de Governança Local: o caso da APA do Sana (Macaé, RJ). 2005. Dissertação (Mestrado em Psicossociologia de Comunidades e Ecologia Social) - Programa de Pós-Graduação em Psicossociologia de Comunidades e Ecologia Social, Instituto de Psicologia, Universidade Federal do Rio de Janeiro, Rio de Janeiro, 2005.

COZZOLINO, L. F. F. Governança na gestão de Unidades de Conservação: Democratização na esfera pública ou legitimação de poder? 2014. 272 f. Tese apresentada ao Programa de Pós-Graduação EICOS, Instituto de Psicologia, Universidade Federal do Rio de Janeiro, como requisito para a obtenção do grau de Doutor em Psicossociologia das Comunidades e Ecologia Social, Rio de Janeiro, 2014.

GRAHAM, J.; AMOS, B.; PLUMPTRE, T. W. Governance principles for protected areas in the 21st century. Ottawa: Institute on Governance, Governance Principles for Protected Areas, 2003. 50 p.

HARMON, D. What does IUCN's protected area definition actually mean? In: DUDley, N.; STOLTON, S., Editors. Defining Protected Areas: an international conference in Almeria. Spain: International Union for Conservation of Nature and Natural Resources, 2008. p. 28-30. 
ICMBio. O Contrato de Concessão de Direito Real de Uso (CCDRU) nas Unidades de Conservação federais. Brasília, DF: ICMBio, 2019. Disponível em: https://www.icmbio.gov.br/portal/images/stories/comunicacao /publicacoes/publicacoes-diversas/o_contrato_de_concessao_de_direito_real_ de_uso_ccdru_nas_ucs_federais.pdf. Acesso em: 07 abr. 2019.

MATIAS-PEREIRA, J. A governança corporativa aplicada no setor público brasileiro. Administração Pública e Gestão Social, Viçosa, v. 2, n. 1, p. 109 $134,2010$.

MULONGOY, K. J.; CHAPE, S. Protected areas and biodiversity: an overview of key issues. Cambridge, UK; Montreal, Canada: IUCN, 2004. 56 p.

PUREZA, F.; PELLIN, A.; PADUA, C. Unidades de conservação: fatos e personagens que fizeram a história das categorias de manejo. Nazaré Paulista: IPÊ; São Paulo: Matrix Editora, 2015.

VALLEJO, L. R. Tempo, espaço e contradições na proteção das áreas naturais: as políticas públicas e a conservação ambiental no Estado do Rio de Janeiro (1975 a 2002). Niteroi: Editora Alternativa, 2017. 224 p.

WORLD BANK. Governance and development. Washington: The World Bank, 1992. 69 p.

WORBOYS, G. L.; LOCKWOOD, M.; KOTHARI, A.; FEARY, S.; PULSFORD, I. (ed.). Protected area governance and management. Camberra: ANU Press, 2015. 994 p. 